\title{
Greetings from AFES
}

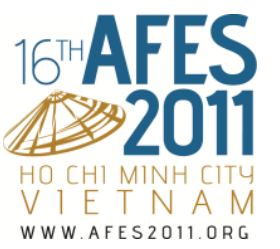

Dear Colleagues and Friends,

On behalf of the ASEAN Federation of Endocrine Societies and the local Organizing Committee, it is my pleasure to welcome you to the $16^{\text {th }}$ Congress of the ASEAN Federation of Endocrine Societies. Building from successes of the preceding congresses in Kuala Lumpur and Bangkok, this Congress continues to be the leading scientific meeting for colleagues engaged in endocrinology in Southeast Asian countries, and will provide a legacy for those who have come to participate in the meeting.

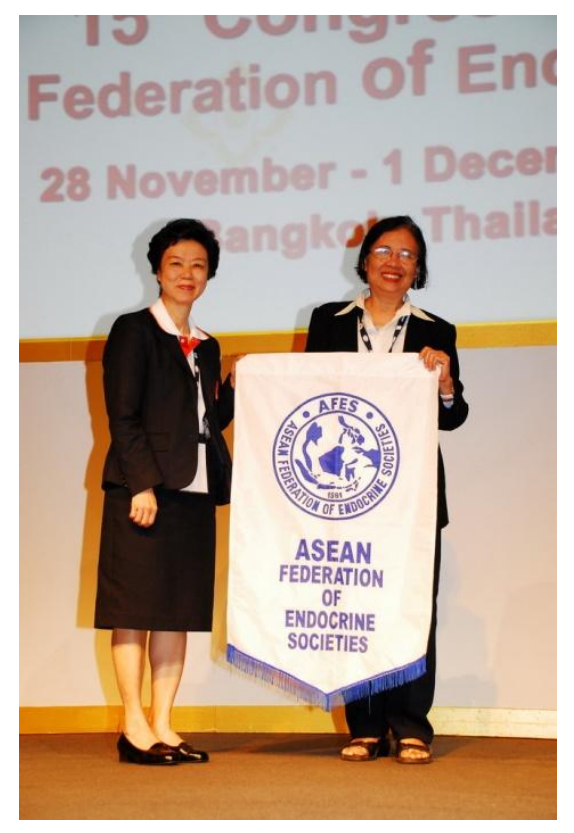

ASEAN countries collectively represent one of the most dynamic economies and health transitions in the world. With a population of approximately 600 million people (i.e., 9\% of the world population), and a combined GDP of $\$ 1.8$ trillion, the ASEAN economy is ranked as the 9th largest economy in the world and the 3rd largest in Asia. Although the degree of economic development is different among member countries, rapid urbanization and aging of population are common trends in all ASEAN countries. At present, the proportion of population aged 60 years and above in ASEAN countries is around $7 \%$, and it is projected that this proportion will reach $\sim 15 \%$ by 2040. With this increase in the aged population, Southeast Asia together with Asia as a whole is emerging as the epicentre of epidemic obesity and diabetes. In 2000, the number of individuals with type 2 diabetes in the Asia Pacific region was estimated to be 30 million, accounting for $20 \%$ of the world diabetic cases. In 2010, the number of diabetic individuals in the Asia Pacific region was estimated at 130 million, which is more than $50 \%$ of the world prevalence. Moreover, the prevalence of osteoporosis in ASEAN populations is as high as in any other Caucasian populations. Thus, the aging population with its adverse health consequences has many public health implications, and presents a unique opportunity for endocrinologists to engage in research and clinical care.

It is perhaps reasonable to say that by and large, endocrinology research in ASEAN countries is not as advanced as in western countries. Moreover, prevalence of and risk factors for common diseases have not been well documented. However, emerging evidence so far has suggested that characteristics of diseases in ASEAN populations are somewhat different from Caucasian populations. For example, Asian diabetics are younger, have lower body mass index, and are often clustered among those in higher socio-economic groups compared with Caucasian populations. The 130 abstracts presented in this Congress represent a collective effort to document the magnitude, risk factors, treatment and prevention of endocrine disorders not just in ASEAN populations but also in non-ASEAN populations.

Translational research is important for ASEAN countries. Therefore, the theme of the $16^{\text {th }}$ AFES Congress is "Translating Endocrinology Research into Clinical Care." With this theme as a guiding principle, the Congress has several official and satellite sessions on basic and applied research, where the most up-to-date information regarding the science and advances in endocrinology, and particularly, clinical care will be presented by leading ASEAN and international scientists. You will have the opportunity to refresh your knowledge and to meet and interact with leading scientists and physicians of endocrinology.

Ho Chi Minh City or Saigon is considered The Orient Pearl, and Saigonese are well-known for being hospitable and friendly people. I hope you will take a little extra time to enjoy the beauty of Saigon and unique cuisine of Vietnam. With that in mind, I wish you the best and have a great scientific exchange, and more importantly, have great fun at this conference, no matter what you accomplish.

I would like to thank everyone who has come to the Congress. Your participation is valuable to the continued success of the Congress.

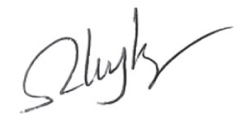

\section{Nguyen Thy Khue}

Chair, AFES 2011 local Organizing Committee

President of the Vietnamese Association of Diabetes and Endocrinology 